\title{
lonospheric TEC Response to Geomagnetic Storms Occurred on 15-20 March 2013 and 2015 over the Eastern Africa Region
}

\author{
Emmanuel Daudi Sulungu ${ }^{1, *}$, Christian Uiso ${ }^{2}$ \\ ${ }^{1}$ Department of Physics, College of Natural and Mathematical Sciences, The University of Dodoma, Dodoma, Tanzania \\ ${ }^{2}$ Department of Physics, College of Natural and Applied Sciences, University of Dares Salaam, Dares salaam, Tanzania
}

Email address:

edsulungu@gmail.com (E. D. Sulungu)

${ }^{*}$ Corresponding author

\section{To cite this article:}

Emmanuel Daudi Sulungu, Christian Uiso. Ionospheric TEC Response to Geomagnetic Storms Occurred on 15-20 March 2013 and 2015 over the Eastern Africa Region. American Journal of Environmental Science and Engineering. Vol. 3, No. 4, 2019 , pp. $103-111$. doi: 10.11648/j.ajese.20190304.16

Received: April 12, 2019; Accepted: May 29, 2019; Published: December 13, 2019

\begin{abstract}
In this paper we present characteristics of the ionosphere over eastern Africa region in response to two geomagnetic storms of March 2013 and March 2015 that occurred at the same date and time but with different intensities. Ionospheric TEC has been derived from the IGS network of ground based dual-frequency GPS receivers from four stations, namely Eldoret $\left(0.29^{\circ} \mathrm{N}, 35.29^{\circ} \mathrm{E}\right)$, Dodoma $\left(6.19^{\circ} \mathrm{S}, 35.75^{\circ} \mathrm{E}\right)$, Malindi $\left(2.99^{\circ} \mathrm{S}, 40.19^{\circ} \mathrm{E}\right)$ and Mtwara $\left(10.26^{\circ} \mathrm{S}, 40.17^{\circ} \mathrm{E}\right)$ within the Eastern Africa region. The interplanetary magnetic field (IMF) Bz and corresponding Dst index, solar wind speed (Vsw) and density (Np) were used to represent the evolution of the storm events. Our results showed that, the behavior of the ionosphere over eastern Africa region during the two geomagnetic storms was similar. During both storms the main phases occurred on $17^{\text {th }}$ of March. However, the main phase of the storm in 2015 had more intensity than that of 2013 but the same duration, and they were followed by a long-duration slow recovery with values that did not return to levels prior to the onset of the storm. The enhancement and reduction of TECv were observed at almost all stations at different times. The results from both storms also show that, there was a pre-reversal enhancement especially at stations that lie close to the equatorial region compared to the stations far from the equatorial region.
\end{abstract}

Keywords: Geomagnetic Storm, Total Electron Content (TEC), Interplanetary Magnetic Field (IMF), Solar Wind

\section{Introduction}

The major source of the control and the driver of the weather and climate of the near earth space is the sun. It drives the magnetosphere, thermosphere and ionosphere of the earth by its energy source [1]. The solar windmagnetosphere-ionosphere form a single system that is driven by the energy and momentum released by the solar wind to the ionosphere through the magnetosphere, a concept that is known as "solar wind - magnetosphere - ionosphere coupling" [2]. Here solar wind is referred to as a continuous flow of plasma which comes out of the sun to the Earth's atmosphere at a speed in a range of $\sim 300-700 \mathrm{~km} / \mathrm{s}$ and consists of electrons and protons which are equal in proportion [3].
Geomagnetic storm is caused by the interaction between the solar wind and the magnetosphere under southward turning IMF (Bz). As this happens, a rapid increase of magnetic reconnection processes occurs at the magnetopause [4]. When $\mathrm{Bz}$ is strongly negative, open field lines are produced by magnetic reconnection between the IMF and the geomagnetic field which allow the passage of mass, energy and momentum from the solar wind to the Earth's magnetosphere. This results into more solar wind energy input into all regions of the earth-atmosphere system, resulting into a geomagnetic storm [5].

During geomagnetic storm events, intense electric fields are dissipated along geomagnetic field lines to the highlatitude ionosphere. This results in prompt penetration of an electric field from high latitudes to the mid- and low-latitudes 
[6]. This prompt penetration electric field is directed eastward during the daytime to the dusk sector and westward in the nighttime to the dawn sector. It has been established that, when geomagnetic storms occur, it can affect satellite communication links and navigation systems by reducing positional accuracy, navigational accuracy and tracking performance for the satellite [7].

Studies have shown that, there are strong disturbances induced in the F-region of the ionosphere during the periods of strong geomagnetic storms [8]. These perturbations cause large enhancements and reduction of electron density at the F2 region described as positive and negative ionospheric storm effects respectively. A long-duration positive ionospheric storm is commonly related to the neutral wind of large scale thermospheric circulation directed equatorward, while a negative ionospheric storm is associated to the variation in composition of the neutral gas which increases the ratio of $\mathrm{O} / \mathrm{N} 2$ at high- and mid-latitude during geomagnetic storms [9].

In their study on GPS derived ionospheric TEC response to geomagnetic storm on 24 August 2005 at Indian low latitude stations, Kumar and Singh [10] revealed the enhancement in TECV which showed positive storm effect. They attributed this feature to local prompt penetration electric field and modified fountain effect. Ngwira et al. [8] showed that, the positive storm enhancement on 25 and 27 July 2004 over South Africa lasted over 9 and 7 hours respectively, and classified both as long-duration positive storm effects. Further, they observed larger plasma density enhancement in the Southern (winter) hemisphere than in the Northern (summer) hemisphere and attributed this to the summer-to-winter trans-equatorial neutral winds that move the plasma density to the winter hemisphere across the equator. Simi et al. [9] on their study on ionospheric response to a geomagnetic storm of November 8-10, 2004 over India, concluded that, storm induced changes in $\mathrm{O} / \mathrm{N} 2$ and the mechanical effect of neutral winds are responsible for the electron density distribution modulation in the equatorial ionization anomaly (EIA) region, and not by the anticipated disturbance induced changes in the fountain effect. Maruyama et al. [11] in their efforts to model the storm-time electrodynamics of the low-latitude ionospherethermosphere system have found that, usually the penetration effect is prevailing during the early phase of the storm and dayside, and can have longer lifetime when the IMF $\mathrm{Bz}$ is large and negative. Their findings also revealed that during the night, the storm is due to both penetration and disturbance dynamo. They lastly found that, during the later stage of the storm and dayside, the reduction is produced mainly by the disturbance dynamo mechanism as compared to the earlier stage. Jain et al. [1] on their study of the response of TEC during severe geomagnetic storms near the crest of equatorial ionization anomaly (EIA) in India reached the conclusion that, TEC deviations during the main phase of the storm were observed to be associated with prompt penetration electric fields brought about by under-shielding and over-shielding conditions, and the formation of wave like features in TECv is caused by the travelling ionospheric disturbances (TID's), while thermospheric composition changes were responsible to the suppression in $\mathrm{TECV}$ observed and also probably the disturbance dynamo electric fields contributed to this effect. Adewale et al. [12] did a study on the storm periods between April 2000 and November 2007 at Libreville, Gabon, and observed positive and negative storm effects during the whole periods of the storm. They concluded that, the occurrence of the positive ionospheric storm effects is contributed by the prompt electric field, and that the development of the positive and negative storms did not follow a fixed trend, regardless of storm onset times. A study by Olwendo et al. [13] shows that the after sunset storm time ionospheric perturbations of penetration electric field may result in a strong negative ionospheric storm effect on the subsequent day depending on what time and how long the recovery phase evolves.

The purpose of this study is therefore to assess the observed characteristics of the vertical total electron content (TECv) in response to two geomagnetic storm events occurred during 15 - 20 March 2013 and 15 - 20 March 2015 between geographical latitudes $0.29^{\circ} \mathrm{N}$ and $10.26^{\circ} \mathrm{S}$ (geomagnetic latitudes $9.17^{\circ} \mathrm{S}$ and $20.35^{\circ} \mathrm{S}$ ) and geographical longitudes $35.29^{\circ} \mathrm{E}$ and $40.17^{\circ} \mathrm{E}$ (geomagnetic longitudes $107.00^{\circ} \mathrm{E} 111.25^{\circ} \mathrm{E}$ ) over the eastern Africa region.

\section{Data and Methods of Analysis}

In this study, ionospheric TEC has been derived from the IGS network of ground based dual-frequency GPS receivers within the Eastern Africa region. Stations used were Eldoret $\left(0.29^{\circ} \mathrm{N}, 35.29^{\circ} \mathrm{E}\right.$, geomagnetic latitude of $\left.9.17^{\circ} \mathrm{S}\right)$, Dodoma $\left(6.19^{\circ} \mathrm{S}, 35.75^{\circ} \mathrm{E}\right.$, geomagnetic latitude of $\left.16.10^{\circ} \mathrm{S}\right)$, Malindi $\left(2.99^{\circ} \mathrm{S}, 40.19^{\circ} \mathrm{E}\right.$, geomagnetic latitude of $\left.12.42^{\circ} \mathrm{S}\right)$ and Mtwara $\left(10.26^{\circ} \mathrm{S}, 40.17^{\circ} \mathrm{E}\right.$, geomagnetic latitude of $\left.20.35^{\circ} \mathrm{S}\right)$, and data were obtained from the UNAVCO website [22]. Figure 1 presents the map of Africa showing the locations of these stations in the region.



Figure 1. A map of Africa showing stations used in this study. 
These GPS data were processed into TEC using the GPSTEC processing software developed at Institute for Scientific Research, Boston College, U.S.A. by Gopi Krishna Seemala [23]. This software calculates the slant TEC (TECs) along the path of the GPS signals with pseudoranges observables $\mathrm{P}_{1}$ and $\mathrm{P}_{2}$ on L1 and L2 signals, with their corresponding high and low GPS frequencies $f_{1}$ and $f_{2}$ respectively using the equation;

$$
T E C=\frac{1}{40.3}\left(\frac{f_{1}^{2} f_{2}^{2}}{f_{1}^{2}-f_{2}^{2}}\right)\left(P_{2}-P_{1}\right)
$$

It reads raw data, processes cycle slips in phase data, reads satellite biases, calculates receiver bias, and calculates the interchannel biases for different satellites in the receiver. In order to eliminate the effect that might be caused by multipath; elevation angle $>20^{\circ}$ was used. The TECs were transformed into vertical TEC (TECv) by assuming the ionosphere to be compressed into a thin shell at a shell height $h$, where in this study it is taken at $350 \mathrm{~km}$. TECv is obtained from the TECs by use of a mapping function (equation 2) which takes the curvature of the Earth into account [14].

$$
T E C v=M(e) \times T E C s
$$

Where.

$$
M(e)=\left[1-\left(\frac{\cos (e)}{1+h / R_{E}}\right)^{2}\right]^{\frac{1}{2}}
$$

Here $e$ is an elevation angle of a satellite, $h$ is ionospheric shell height, and $\mathrm{R}_{\mathrm{E}}$ is the Earth's mean radius.

In order to study the variations of $\mathrm{TECV}$ during the storm, TECv from the mean of the 5 international quiet days of the respective month was also included in the analysis so as to assess the effects of the storm on $\mathrm{TECV}$ during the storm in comparison to the quiet days. The quiet days of the month were obtained from World Data Center for geomagnetism [24].

On the other hand, hourly values of embedded interplanetary magnetic field (IMF) Bz (in Geocentric Solar Magnetospheric (GSM) co-ordinates), and corresponding Dst index, solar wind speed (Vsw) and density (Np) were used. These parameters were used to represent the evolution of the storm events that occurred on 15 - 20 March, 2013 and 2015 to identify rapid direction changes in the IMF Bz-component, rapid proton number and velocity changes in the solar wind. The hourly Dst indices values were obtained from World data Center database [25].

On the other hand, the southward interplanetary magnetic field $\mathrm{Bz}$ and the solar wind parameters, Vsw and $\mathrm{Np}$, were obtained from ACE level 2 satellite website [26].

ACE is a NASA Explorers mission which provides data for studying matter comprising energetic particles from the solar wind, the interplanetary medium, and other sources.
Real-time data from ACE is used by the NOAA Space Weather Prediction Center to improve forecasts and warnings of solar storm. The hourly values of all the parameters were plotted against time (UT).

\section{Results}

In this study, the characteristics of the ionosphere following the occurrence of geomagnetic storms occurred during 15 - 20 March, 2013 and 15 - 20 March 2015 are presented and discussed. These two storms occurred in different years, but at the same day and time.

\subsection{The Geomagnetic Storm of 15-20 March 2013}

This section presents the characteristics of the geomagnetic storm occurred during the period of $15-20$ March 2013 with the corresponding IMF-Bz, solar wind speed (Vsw) and density (Np) characteristics. CME was erupted from the solar active region AR1692 on $15^{\text {th }}$ March 2013 produced an M1-class solar flare with a peak emission at 06:00 UT [27]. This disturbance reached the earth on $17^{\text {th }}$ March 2013 as shown in figure 2. During this time, the solar wind speed abruptly increased from about $420 \mathrm{~km} / \mathrm{s}$ to about $660 \mathrm{~km} / \mathrm{s}$ which indicated the commencement of the Storm sudden commencement (SSC) (shock wave). At the same time the solar wind density was also observed to rapidly increase from $3 \mathrm{~cm}^{-3}$ to about $14 \mathrm{~cm}^{-3}$. While these solar wind parameters observed to abruptly increase, the IMF-Bz was highly disturbed and pointed southwards and reach a value of $-11 \mathrm{nT}$ at 09:00 UT on the same day, before it turns again northward to a value of about $3 \mathrm{nT}$ at 10:00 UT. After the attainment of this value, it fluctuated in north-south direction and then pointed southward again to attain a value of $-10 \mathrm{nT}$ at 18:00 UT.

The main phase of the storm ended at 22:00 UT on $17^{\text {th }}$ March 2013, where the minimum value reached was $-132 \mathrm{nT}$ (Figure 2, upper panel), and this storm was categorized as the strong storm. The recovery phase took place as after the main phase up to $20^{\text {th }}$ of the same month, where there was another fluctuation as can be observed on Dst index (Figure 2). Further, during recovery phase, solar wind speed and density were observed to decrease continuously to attain their minimum values of about $390 \mathrm{~km} / \mathrm{s}$ and $1 \mathrm{~cm}^{-3}$ respectively. However, during recovery phase, the IMF-Bz was observed to fluctuate in north-south direction with small amplitudes.

Figure 3 shows the variations of ionospheric TECv during the storm of 15 to 20 March 2013 compared with mean quiet days TECv measured at four different stations over the Eastern Africa region. The figure shows that, at Eldoret (geomag. lat. $9.17^{\circ} \mathrm{S}$ ), $\mathrm{TECv}$ was enhanced from the beginning of the storm up to the recovery day, except for few cases. For example: on $17^{\text {th }}$ at $18: 00$ hours TECv was reduced with a percentage deviation of $\sim 22 \%$ from the quiet day TECv (Figure 4). During the main phase of the storm, TECv enhancement during the mid-day hours reached $\sim 70$ TECU, with a percentage deviation of $\sim 25 \%$ (Figure 4). Further, during the recovery phase, there was a higher 
percentage deviation, $\sim 48 \%$, compared to any other day since the beginning of the storm. Other higher values of TECV observed during the main phase of the storm in comparison to the higher peaks during the quiet day were as follows:
Malindi ( $\sim 65$ TECU during the storm and $\sim 60$ TECU during the quiet day), Dodoma ( $\sim 60$ TECU during the storm and $\sim 65$ TECU during the quiet day) and Mtwara ( $\sim 60$ TECU during the storm and $\sim 62$ TECU during the quiet day).

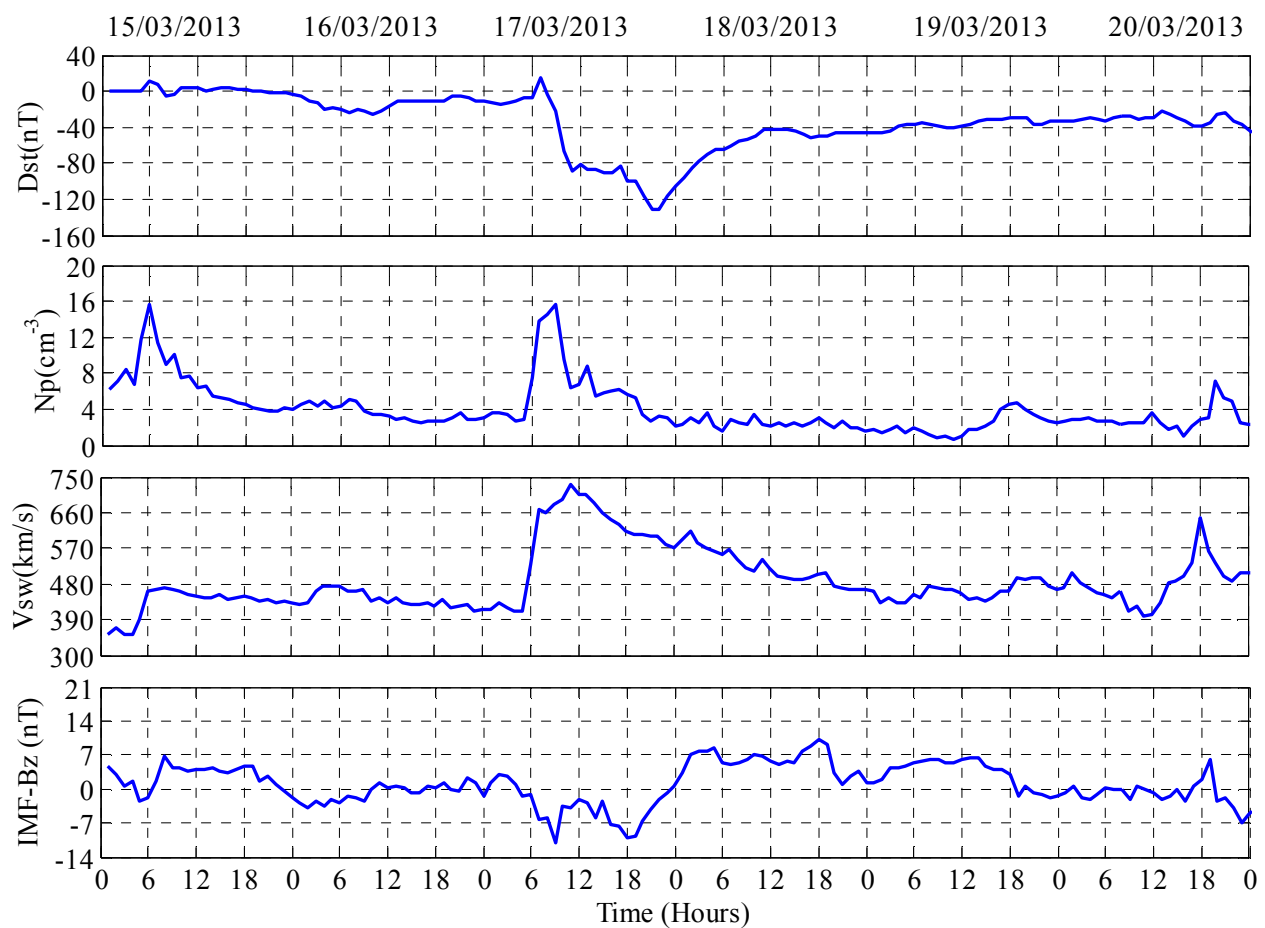

Figure 2. Variations of Dst index, IMF Bz, Solar wind velocity (Vsw) and Proton density (Np) during 15- 20 March, 2013.

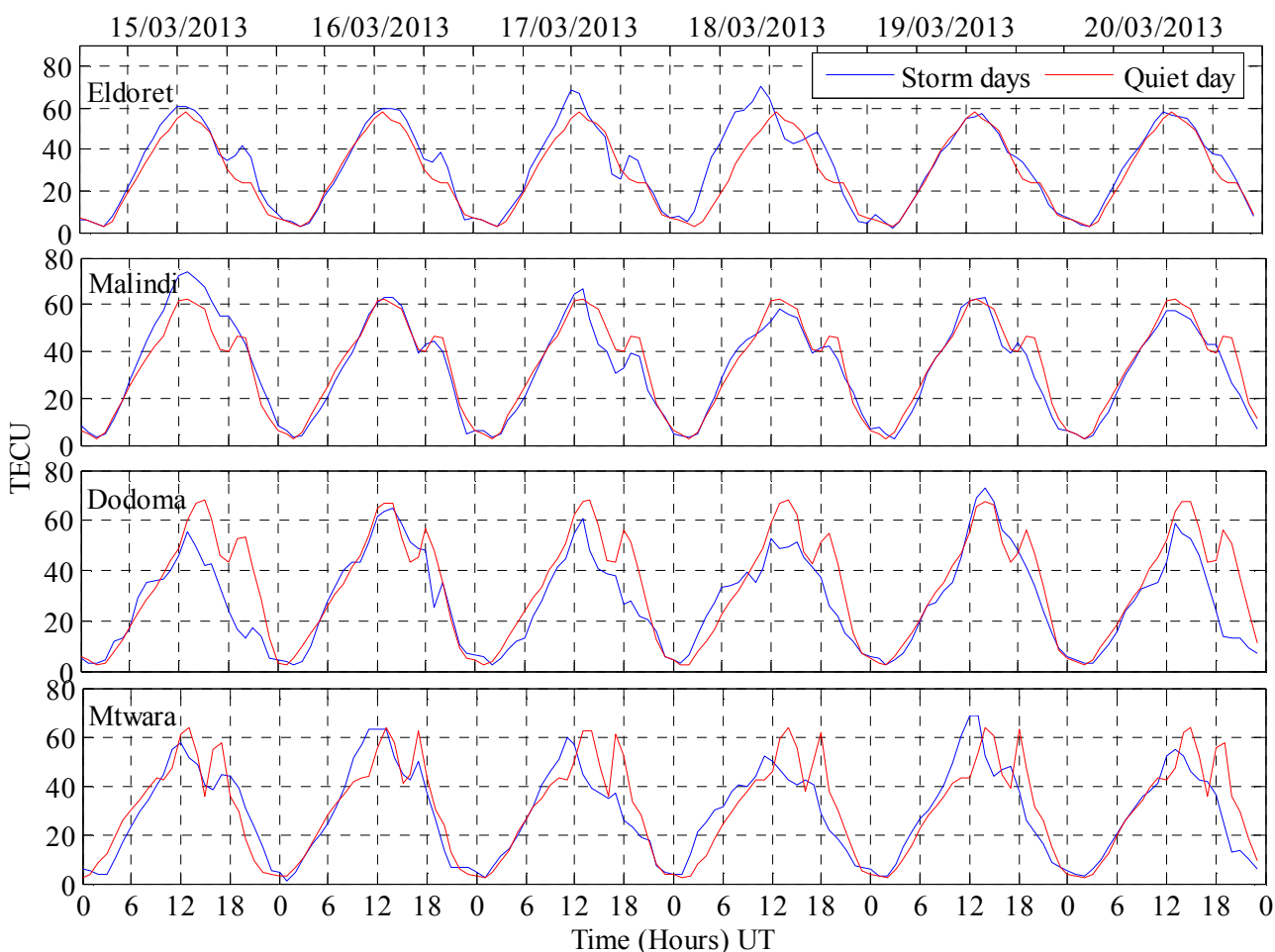

Figure 3. Variations of TECv during the storm days and during quiet days for March 2013.

In addition, TECv instabilities were observed during the storm day, having several peaks especially at Dodoma (geomag. lat. $16.10^{\circ} \mathrm{S}$ ) and Mtwara (geomag. lat. 20.35 ${ }^{\circ} \mathrm{S}$ ). These features were also observed at these stations during 
other days since the beginning of the storm. Furthermore, TECV was observed to be reduced at Dodoma and Mtwara during afternoon hours as can be observed in figure 3 . The higher reductions in TECv were observed during pre-reversal enhancement, i.e. between 18:00 and 19:00 (Figure 4 also illustrates this).

Another thing worth noting is that, on $15^{\text {th }}$ March, the day where $\mathrm{Bz}$ was observed to point southwards, Vsw to increase and $\mathrm{Np}$ to sharply increase, TECV was observed to be enhanced during the mid-day in comparison to quiet day, except at Dodoma and Mtwara where there was a reduction. This effect of Bz, Vsw and $\mathrm{Np}$ to TECv on this day is the same as that occurred during the main phase, and these parameters had the same characteristics on these two days. This shows that, changes in solar wind parameters and IMF$\mathrm{Bz}$ have high influence on $\mathrm{TECV}$ variations. The enhancement and reduction of TECv were also revealed on other days at different stations as shown in figure 3 with their corresponding percentage deviations from quiet day TECV as shown in figure 4.

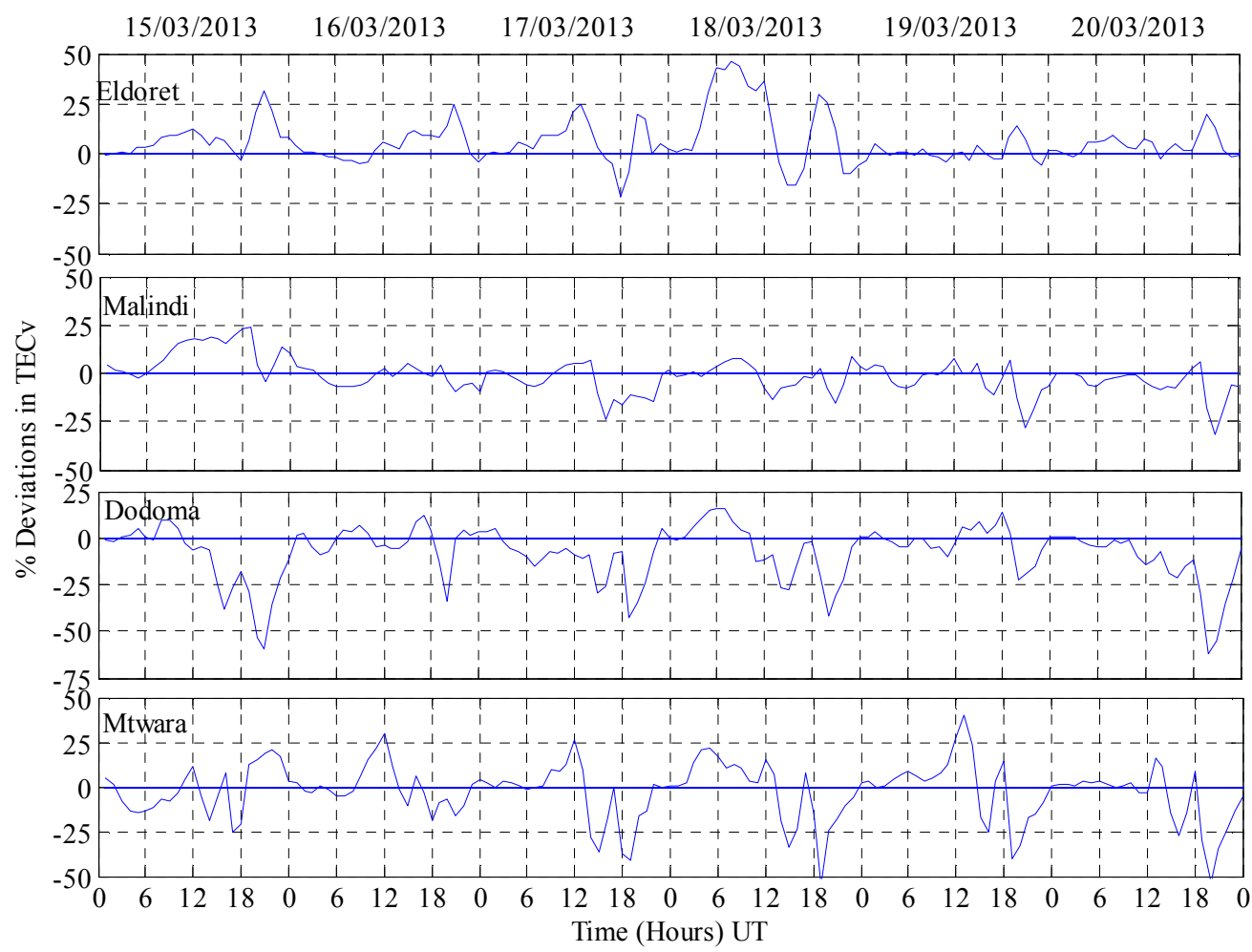

Figure 4. Percentage deviations of disturbed days TECv from the mean of 5 quite days TECv for March 2013.

\subsection{The Geomagnetic Storm of 15-20 March, 2015}

On $17^{\text {th }}$ March, 2015, an incoming CME propelled into space by sunspot AR2297 hit Earth's Magnetic field at around 04:30 UT [27]. From figure 5 it is observed that, during this time, IMF-Bz was disturbed and forced to point northwards from about $3 \mathrm{nT}$ to above $22 \mathrm{nT}$, it was then fluctuated in north-southwards directions before attaining the value of about $-19 \mathrm{nT}$. This value was attained during the main phase of the storm at around 22:00 UT. At the same time, Vsw was observed to abruptly increase from about 400 $\mathrm{km} / \mathrm{s}$ to $630 \mathrm{~km} / \mathrm{s}$ indicated the commencement of the SSC (shock wave). Further, $\mathrm{Np}$ was also observed to increase from $14 \mathrm{~cm}^{-3}$ to $42 \mathrm{~cm}^{-3}$. The minimum Dst value reached was $-223 \mathrm{nT}$ (Figure 5, upper panel) and occurred at 22:00 UT. This storm was categorized as the severe storm. The recovery phase took place as after the main phase up to $20^{\text {th }}$ of the same month. In addition, during recovery phase, solar wind speed remains higher and solar wind density was observed to decrease continuously to attain their minimum value of about $3.5 \mathrm{~cm}^{-3}$.
However, during recovery phase, the IMF-Bz was observed to fluctuate in north-south direction with small amplitudes maintaining the value close to $0 \mathrm{nT}$ throughout the day. Figure 6 shows the variations of ionospheric TECv during the storm of 15 to 20 March 2015 compared to the mean quiet days TECv measured at four different stations over the Eastern Africa region. The general observation from the figure shows that, both storm days' TECv and mean quiet days TECv are characterized by consistent minimum diurnal variation during presunrise hours between 02:00 and 03:00 UT (05:00 and 06:00LT), rises steeply during the sunrise period at approximately 04:00 UT $(07: 00 \mathrm{LT})$ to the maximum peak during the daytime, between 12:00 and 14:00 UT, followed by a decrease to a minimum during nighttime. It was further observed that, during the recovery phase of the storm, TECv values were higher than the values of the mean quiet days at all stations (Figure 6). The percentage deviations of storm day TECv from the quiet day TECv were $\sim 35 \%$ at Eldoret, $\sim 12.5 \%$ at Malindi, $\sim 25 \%$ at Dodoma and $\sim 12-25 \% \%$ at Mtwara (Figure 7). In addition, the TECv curves from all the stations were observed to have two peaks, 
one at around 12:00 UT at Eldoret and Malindi, whereas at Dodoma and Mtwara it occurred a bit earlier before 12:00 UT. The second peak was observed to occur between 16:00 UT and 19:00 UT. On the other hand, on 19 ${ }^{\text {th }}$ March from around 2:00 to 10:00, TECV were observed to be enhanced at
Malindi, Dodoma and Mtwara in comparison to mean quiet days' TECV values, whereas after this time it was reduced. The reduction effect was observed to increase with the increase in latitudes southwards.

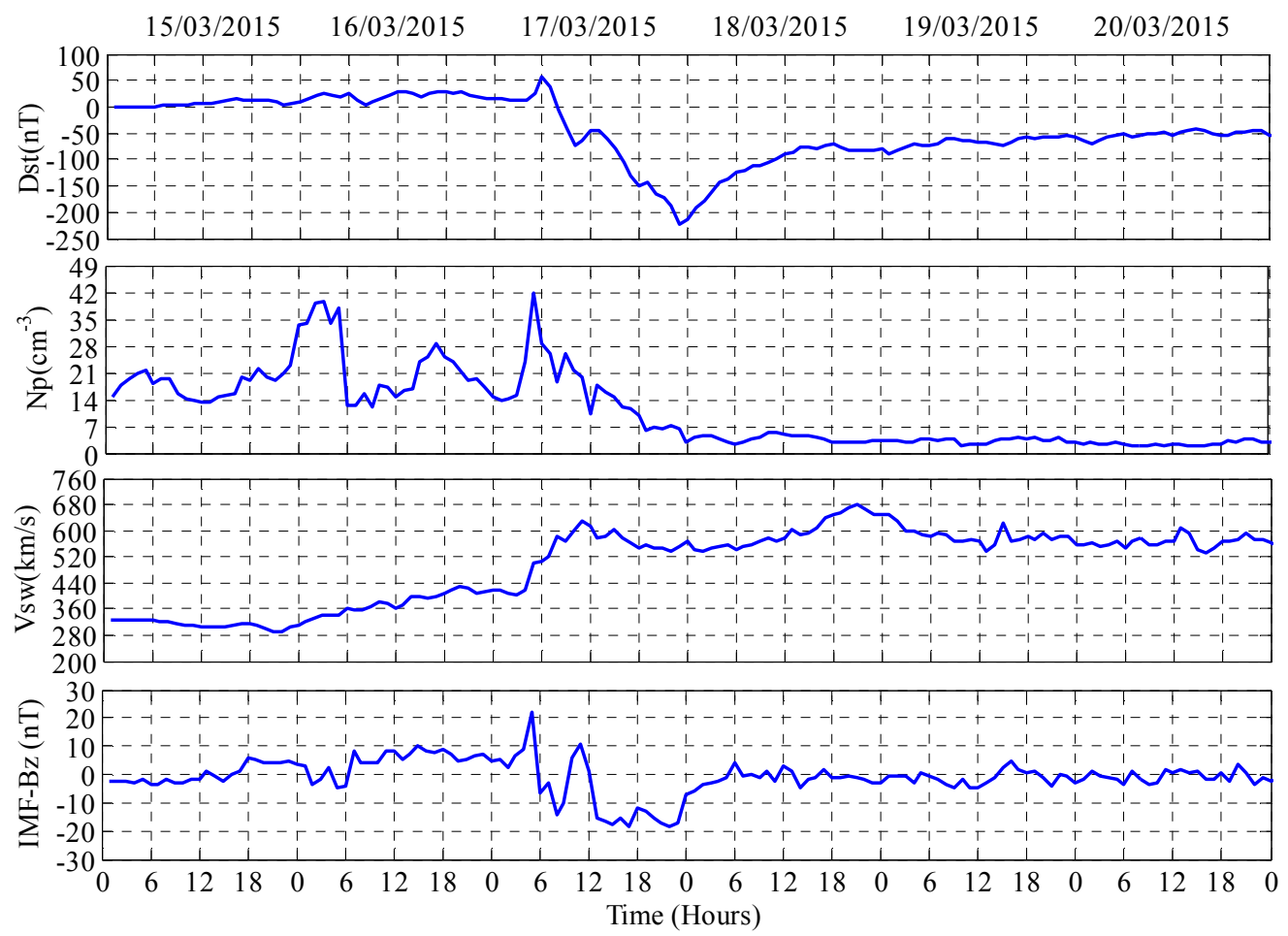

Figure 5. Variations of Dst index, IMF Bz, Solar wind velocity (Vsw) and Proton density (Np) during 15-22 March, 2015.

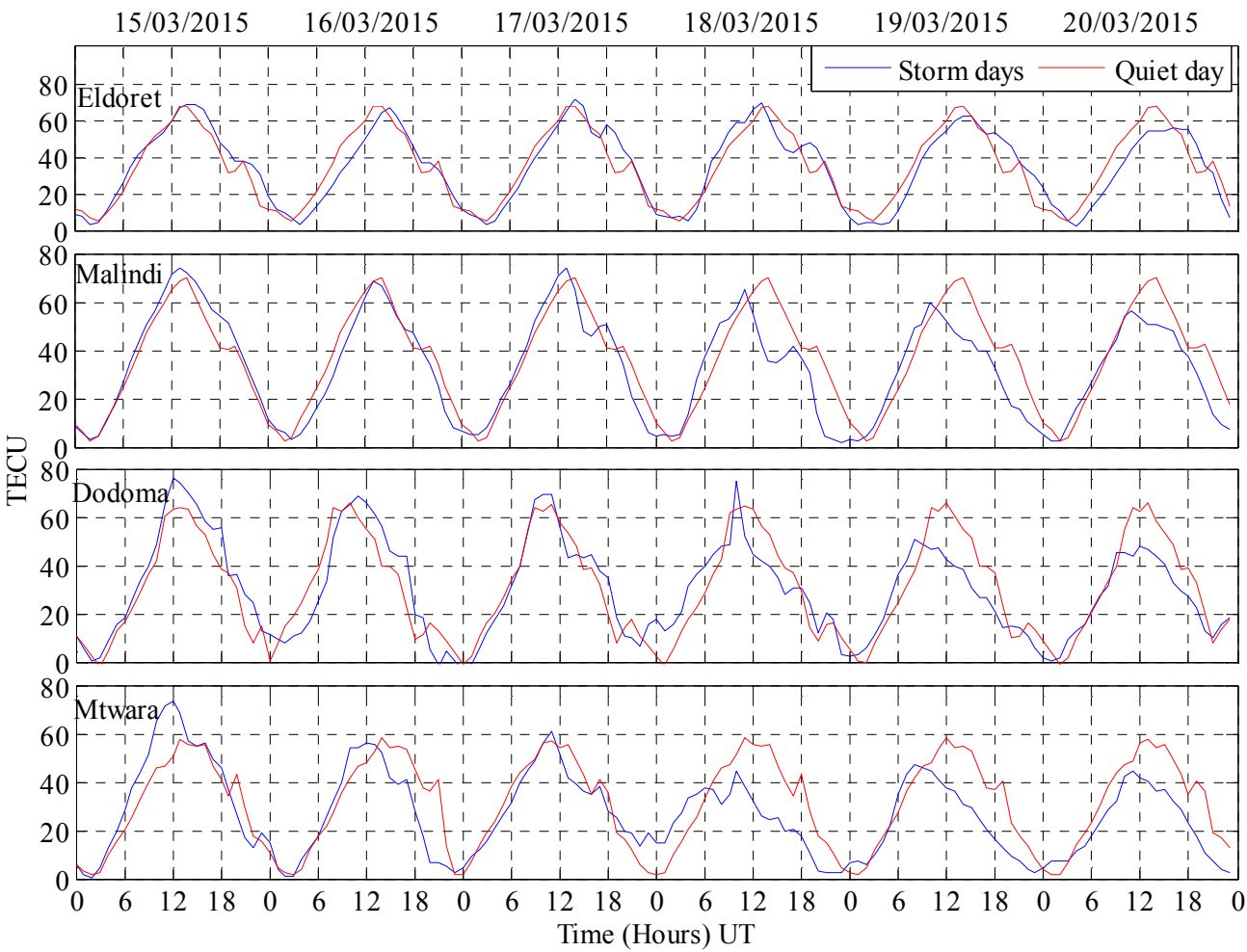

Figure 6. Variations of TECv during the storm days and during quiet days for March 2013. 




Figure 7. Percentage deviations of disturbed days TECV from the mean of 5 quite days TECV for March 2015.

\section{Discussion}

In this paper, we have reported ionospheric storm effects during the geomagnetic storms of 15-20 March 2013 and 15-20 March 2015. The observations revealed that, the geomagnetic storm occurred in 2015 had more intensity and duration than that of 2013. These intensities for 2013 and 2015 storms were $-132 \mathrm{nT}$ and $-223 \mathrm{nT}$ respectively and their durations were 14 hours 17 hours respectively. The main phases from both storms were followed by a long-duration slow recovery with values that did not return to levels prior to the onset of the storm.

One of the main factors that influence the strength of a magnetic storm is the direction and strength of the interplanetary magnetic field (IMF) [15]. If this turns southwards it allows much more energy into the Earth's magnetic field, but if it turns northwards it can effectively shut down a magnetic storm. This is because several thermospheric parameters, such as composition, temperature and circulation are changed due to the input of energy into the ionosphere during geomagnetic disturbances. The electron concentration is influenced by the change in composition in the F2 region, which also affects the TECv. In this case, for March 2015 geomagnetic storm, the IMF went strongly southwards for well over 12 hours reaching a value of $-20 \mathrm{nT}$ allowing a lot of energy to flow into the Earth's magnetic field as compared to that of March 2013 which reached a value of $10 \mathrm{nT}$.

It is clearly presented on the results that, during SSC of the 15 -20 March 2015 geomagnetic storm, IMF-Bz was observed to point northwards before turning southwards during the main phase of the storm. The northward turning is due to the penetration of the dusk-to-dawn (Interplanetary Electric Field) IEF, i.e. the westward IEF, and the southwards turning is due to the penetration of the dawn-to-dusk IEF, i.e. the eastward IEF [16]. During geomagnetic storm, the global distribution of ionospheric currents and electric fields can be altered by the perturbations in the solar wind magnetosphere dynamo and Ionospheric wind dynamo [17]. Prompt penetration of electric fields, also dynamo electric fields from the disturbance neutral winds which occurred for a long period and storm-related changes in ionospheric conductivity, usually affects the E x B drifts [18], leading to variations in the ionospheric parameters at equatorial and low latitudes.

A number of studies suggest that, electric fields, meridional winds, a composition bulge and high latitude particle precipitation are the physical mechanisms that clearly describe the ionospheric response to geomagnetic storms observed at different latitudes [5, 19]. It has been reported that during major magnetic storms there is an instantaneous penetration of electric fields from high latitude to the middle and the equatorial ionosphere [5]. Rao et al. [7] showed that prompt penetration electric fields reach the equatorial ionosphere during the southwards turning of IMF $\mathrm{Bz}$, and when it is stable.

The enhancement of TECV observed and formation of first peak is due to prompt penetration electric field (PPEF) [6, 10]. This PPEF cause the upward stormtime drifts on the dayside and downward drifts on the nightside [13], which results into the maximal uplift of the ionosphere around noon. The dawn-to-dusk PPEF is always directed eastward during the day and enhanced the low latitude ExB drift of the 
ionization [10]. The uplifted plasma then diffuses along the magnetic field lines towards higher altitudes where recombination rates are smaller giving enhanced value of TEC at low latitudes region [4]. Bagiya et al. [19] in their study on geomagnetic storm of August 24, 2005 using GPS data from Rajkot station $\left(22.29^{\circ} \mathrm{N}, 70.74^{\circ} \mathrm{E}\right)$; they observed that, $\mathrm{TECv}$ enhancement is due to prompt penetration of electric fields during the storm day and thermospheric composition changes and disturbance dynamo electric fields on the preceding recovery day. Similar results were also reported by Jimoh et al. [20] on their study on investigation of ionospheric response to geomagnetic storms over a low latitude station, Ile-Ife, Nigeria. They attributed this with the high energy input at high latitudes that produces traveling ionospheric disturbances (TIDs). These TIDs travel equatorward with high velocities and may result in the uplifting of the F layer which influence the increased levels of TECV. Also Huang et al. [21] related the enhancement of $\mathrm{TECV}$ at the mid-day by the strong neutral winds blowing equatorward from the high latitude zone that pushes plasma away from the earth and its neutral atmosphere along the magnetic field lines. This in turn reduces recombination of $\mathrm{O}+$, which requires interaction with a neutral molecule for efficient recombination, thereby increasing the plasma density.

On the other hand, TECV reductions observed are caused by changes in the composition of the neutral atmosphere at ionosphere heights due to heating and upwelling of the lower atmosphere with its molecular-rich composition. This results into a decrease in the $\mathrm{O} / \mathrm{N} 2$ ratio and enhances the recombination of the $\mathrm{O}+$ plasma [21].

The results presented also showed the pre-reversal enhancement in TEC. This effect is an outcome of the interaction of the $\mathrm{E}$ and $\mathrm{F}$ region dynamos which results into an enhancement of the eastward electric field before it turns westward at dusk [13]. The pre-reversal enhancement increases the vertical drift which makes the ionosphere to be lifted to higher altitude where the ratio of production to loss of electrons is greater and the transport of ions is dominant.

The observations from the results also showed that, for both storms presented, the main phases were mostly intensified in the beginning of the day hours and continued during the daytime. This tendency might have been due to continuous feeding of energy into the ionosphere during the daytime when production is still predominant, leading to the elongated disturbances [8].

\section{Conclusions}

In this study, TEC response to two St. Patrick's Day geomagnetic storm events on 15-20 March, 2013 and 15-20 March 2015 have been analyzed. From the analysis of the two storms, it was noted that, the behavior of the ionospheric TEC over eastern Africa region during the two geomagnetic storms was similar. The intensity and duration of the storm occurred in 2015 was higher than that of 2013 storm. The main phases from both storms were followed by a long- duration slow recovery with values that did not return to levels prior to the onset of the storm.

TECV was enhanced from the beginning of the storm up to the recovery day at Eldoret, while it was reduced on $17^{\text {th }}$ at 18:00 hours with a percentage deviation of $\sim 22 \%$. At other stations, there was no any fixed trend of TECv variations during the storm in comparison to the quiet day TECv. At Dodoma and Mtwara TECv instabilities were observed during the storm day, having several peaks.

Prompt penetration electric field (PPEF) is the main cause of the enhancement of TECV and formation of first peak observed. This PPEF cause the upward stormtime drifts on the dayside and downward drifts on the nightside which results into the maximal uplift of the ionosphere around noon. Also, TECv reductions observed are caused by variations in the composition of the neutral atmosphere due to heating and upsurge of the lower atmosphere with its molecular-rich composition. The pre-reversal enhancement observed in TEC is an outcome of the interaction of the $\mathrm{E}$ and $\mathrm{F}$ region dynamos which results into an enhancement of the eastward electric field before it turns westward at dusk.

\section{Acknowledgements}

We express our gratitude to the University Navstar Consortium (UNAVCO) and the World Data Centre for Geomagnetism, Kyoto University, Japan for giving access to GPS data and Dst indices respectively. We thank the ACE science centre for providing the ACE data. We also acknowledge Dr. Gopi Seemala for providing access to the GPS-TEC analysis software used in this work.

\section{References}

[1] Jain A, Tiwari S, Jain S and Gwal A K, TEC response during severe geomagnetic storms near the crest of equatorial ionization anomaly, Indian J Radio Space Phys, 39 (2010) 11-24.

[2] Habarulema J B, A contribution to TEC modeling over Southern Africa using GPS data, (Thesis, University of Rhodes, SA), 2010, 65.

[3] Rathore B S, Gupta C and Parashar K K, Relation between Solar Wind Parameter and Geomagnetic Storm Condition during Cycle-23, Int J Geosc (USA), 5 (2014) 1602.

[4] D'ujanga F M, Baki P, Olwendo J O and Twinamasiko B F, Total Electron Content of the ionosphere at two stations in East Africa during the 24-25 October 2011 Geomagnetic storm, Adv Space Res (UK), 51 (2013) 712-721.

[5] Basu S, Basu Su, Rich F J, Groves K M, MacKenzie E, Coker C, Sahai Y, Fagundes P R and Becker-Guedes F, Response of the equatorial ionosphere at dusk to penetration electric fields during intense magnetic storms, $J$ Geophys Res (USA), 112 (2007) A08308.

[6] Zhao B, Weixing W, Libo L and Tian M, Morphology in the total electron content under geomagnetic disturbed conditions: results from global ionosphere maps. Ann Geophys (France), 25 (2009) 1555-1568. 
[7] Rao P V S R, Krishna S G, Prasad J V, Prasad S N V S, Prasad S V D and Niranjan K, Geomagnetic storm effects on GPS based navigation, Ann Geophys (France), 27 (2009) 2101-2110.

[8] Ngwira C M, McKinnell L, Cilliers P J and Coster A J, Ionospheric observations during the geomagnetic storm events on 24-27 July 2004: Long-duration positive storm effects, $J$ Geophys Res (USA), 117 (2012) A00L02.

[9] Simi K G, Manju G, Haridas M K M, Nayar S R P, Pant T K and Alex S, Ionospheric response to a geomagnetic storm during November 8-10, 2004, Earth, Planet Space (Japan), 65 (2013) 343-350.

[10] Kumar S and Singh A K, GPS derived ionospheric TEC response to geomagnetic storm on 24 August 2005 at Indian low latitude stations, Adv Space Res (UK), 47 (2011) 710-717.

[11] Maruyama N, Sazykin S, Spiro R W, Anderson D, Anghel A, Wolf R A, Toffoletto F R, Fuller-Rowell T J, Codrescu M V, Richmon A D and Millward G H, Modeling storm-time electrodynamics of the low-latitude ionosphere-thermosphere system: Can long lasting disturbance electric fields be accounted for? J Atmos Sol-Terr Phys (UK), 69 (2007) 1197.

[12] Adewale A O, Oyeyemi E O, Adeloye A B, Ngwira C M and Athieno $\mathrm{R}$, Responses of equatorial $\mathrm{F}$ region to different geomagnetic storms observed by GPS in the African sector, $J$ Geophys Res (USA), 116 (2011) A12319.

[13] Olwendo J O, Yamazak Y, Cilliers P, Baki P, Ngwira C M and Mito C, A study on the response of the Equatorial Ionization Anomaly over the East Africa sector during the geomagnetic storm of November 13, 2012, Adv Space Res (UK), 55 (12) (2015) $2863-2872$.

[14] Shim J S, Analysis of Total Electron Content (TEC) variations in the low and middle latitude ionosphere, (PhD Thesis, Department of Physics, Utah State University, USA), 2009, 9.

[15] Zhao B, Wan W, Liu L and Ren Z, Characteristics of the ionospheric total electron content of the equatorial ionization anomaly in the Asian-Australian region during 1996-2004, Ann Geophys (France), 27 (2007) 3861-3873.

[16] de Siqueira P M, de Paula E R, Muella M T A H, Rezende L F C, Abdu M A and Gonzalez W D, Storm-time total electron content and its response to penetration electric fields over South America, Ann Geophys (France), 29 (2011) 1769.

[17] Joshua B W, Adeniyi J O, Adimula I A, Oladipo O A, Olawepo $\mathrm{O} \mathrm{A}$ and Adebiyi S J, Ionospheric response to the storm-time disturbance of 29 May, 2010, Adv Space Res (UK), $53(2014 b) 223$.

[18] Bounsanto M J, Ionospheric storms - a review, Space Sci Rev (Netherlands), 88 (1999) 567.

[19] Bagiya M S, Joshi H P, Lyer K N, Aggarwal M, Ravindra S and Pathan B M, TEC variations during low solar activity period (2005-2007) near the equatorial ionospheric anomaly crest region in India, Ann Geophys (France), 27 (2009) 1047.

[20] Jimoh O E, Yesufu T K and Ariyibi E A, Investigation of Ionospheric Response to Geomagnetic Storms over a Low Latitude Station, Ile-Ife, Nigeria, Acta Geophys (Poland), 64 (3) (2016) 772-795.

[21] Huang C S, Foster J C, Goncharenko L P, Erickson P J, Rideout $\mathrm{W}$ and Coster A J, A strong positive phase of ionospheric storms observed by the Millstone Hill incoherent scatter radar and global GPS network, J Geophys Res (USA), 110 (2005) A06303.

[22] http://seemala.blogspot.com.

[23] http://wdc.kugi.kyoto-u.ac.jp/.

[24] http://wdc.kugi.kyoto-u.ac.jp/qddays/index.html.

[25] http://www.spaceweather.com.

[26] http://www.srl.caltech.edu/ACE/ASC/level2.

[27] http://www.unavco.org/. 